\title{
O USO DO YOUTUBE COMO FORMA DE PROPAGANDA PARA O HOTEL SUL AMÉRICA
}

\author{
Mariana Gaio Lisbôa Telhado
}

Eduardo Picanço Cruz

\section{RESUMO}

Este trabalho aborda o site YouTube, fenômeno da internet deste início de milênio, e que pode ser utilizado como forma de propaganda. Analisamos o caso do Hotel Sul América, que possui vídeos não institucionais no site em questão. Para tal, relembramos os conceitos de marketing, passando por sua história, verificando suas aplicações no mercado e conhecendo o mix de marketing. Em seguida, analisamos as estratégias de promoção. Vimos as principais formas de comunicação entre organização e público-alvo particularmente aprofundando o estudo em mídia, com foco nos principais meios de comunicação e na forma como eles podem interagir. A parti desse ponto, estudamos o YouTube, como ele foi criado, a sua relação com o marketing e alguns pontos importantes do YouTube na mídia. Por fim, destacamos o Hotel Sul América discorrendo sobre a pesquisa de campo elaborada e sobre as respostas do Hotel com relação ao YouTube.

Palavras-chave: Marketing. Mídia. Propaganda. Internet. YouTube. Hotel Sul América.

\begin{abstract}
This article is about the site Youtube, the Internet phenomenon and that can be used as a form of propaganda. We analyze the case of South America Hotel, which has no institutional videos on the site in question. For this, remember the concepts of marketing, through its history, examining its applications in the market and knowing the marketing mix. Then we analyze the strategies for promotion. We saw the main forms of communication between organization and target audience particularly deepening the study of media, with focus on major media, and how they may interact. So, we studied the YouTube, as it was created, its relationship with the marketing and some important points of YouTube in the media. Finally, we present the Hotel South America case, showing the research and the answers of the Hotel with YouTube
\end{abstract}

Key words: Marketing. Media. Advertisement. Internet. YouTube. Hotel Sul America. 


\section{INTRODUÇÃO}

A internet, hoje grande veículo de comunicação, tem se mostrado eficaz no mundo publicitário. Por ser um meio rápido e capaz de atingir um maior número de pessoas num menor espaço de tempo, a internet tem trabalhado como uma ferramenta de propaganda. Apesar de as empresas ainda não entenderem como o YouTube pode ajudar na sua projeção ao seu público-alvo, algumas empresas já conseguiram visualizar esta nova ferramenta e estão apresentando certo interesse em divulgar vídeos que as promovam.

Uma grande forma de propaganda que acontece através do site do YouTube é a disponibilidade do usuário adicionar seus vídeos favoritos no Orkut, que hoje é um dos maiores sites de relacionamentos. Sendo assim, estudamos esta nova ferramenta de propaganda e verificamos sua aplicabilidade para o Hotel Sul América, que é um hotel da cidade de São Lourenço, Minas Gerais, muitos hóspedes são jovens e estão ligados aos avanços da tecnologia e principalmente da Internet.

\section{MARKETING}

Marketing é uma função gerencial, que busca ajustar a oferta da organização a demandas específicas do mercado, utilizando com ferramental um conjunto de princípios e técnicas. E pode ser visto também, como um processo social, pelo qual são reguladas a oferta e a demanda de bens e serviços para atender às necessidades sociais. É, ainda, uma orientação da administração, uma filosofia, uma visão. Essa orientação reconhece que a tarefa principal da organização é satisfazer o consumidor, atendendo a suas necessidades, levando em conta seu bem-estar a longo prazo, respeitadas as exigências e limitações impostas pela sociedade e atendidas às necessidades de sobrevivência e continuidade da organização.

Dessa forma, pode ser entendida como a área do conhecimento que engloba todas as atividades concernentes às relações de troca, orientadas para a satisfação dos desejos e necessidades dos consumidores. Tais necessidades e desejos são satisfeitos mediante a compra de produtos e serviços, esta compra pode ser impulsionada por uma necessidade fisiológica (alimentação, abrigo, frio) ou psicológica (status, segurança, diversão, etc.). Conhecendo e estudando estas motivações ao consumo, as empresas procuram produzir bens e serviços que atendam ao público-alvo. É através do Marketing que as empresas vão conseguir conquistar e fidelizar seus clientes.

Em 1960, a AMA (American Marketing Association) definia Marketing como: "o desempenho das atividades de negócios que dirigem o fluxo de bens e serviços do produtor ao consumidor ou utilizador". Kotler (2003) sugeriu ainda que o conceito de marketing deveria abranger também as instituições não lucrativas. Para Willian Lazer, em 1969, "o marketing deveria reconhecer as dimensões societárias; isto é, levar em conta as mudanças verificadas nas relações sociais". David Luck instituiu, neste mesmo ano, que: "o marketing deveria limitar-se às atividades que resultam em transações de mercado."

Após todo este movimento de expandir o conceito do marketing Kotler (2003) propôs que a essência do marketing é transação, definida como a troca de valores entre duas partes através do seguinte conceito: "Marketing é um processo social e gerencial pelo qual indivíduos e grupos obtêm o que necessitam e desejam através da criação oferta e troca de produtos de valor com outros." 


\section{COMPOSTO DO MARKETING}

O composto de marketing, também chamado de marketing mix, mix de marketing ou composto mercadológico, é o conjunto de instrumentos controláveis pelo gerente de marketing, por meio dos quais ele pode obter melhor ajustamento entre a oferta que sua empresa faz ao mercado e a demanda existente. É o conjunto de ferramentas de marketing que a empresa utiliza para perseguir seus objetivos de marketing do mercado alvo.

A consistência e a coerência entre os vários elementos do mix são fundamentais para o sucesso da empresa. 0 marketing precisa ser integrado, para que a empresa possa aplicá-lo com sucesso.

McCarthy e Perreault (1984) classificaram esta ferramenta em quatro grupos amplos que denominaram os 4Ps do Marketing: produto, preço, praça e promoção. As mudanças modernas fazem alguns autores proporem mudar o termo produto por objeto de marketing, haja vista a possibilidade de elaborar um projeto para um serviço, um lugar, um pessoa, uma idéia, evento, etc.

Outro item que vem sendo discutido é a praça, muitos pesquisadores destacam que seria mais oportuno usar o termo distribuição.

\section{PROMOÇÃO}

Nas comunidades primitivas, o produtor não precisava anunciar seus produtos, já que interagia diretamente com os clientes. Era a comunicação "boca a boca" que divulgava a fama de um artesão. 0 produtor não exercia nenhuma influência sobre o conteúdo da mensagem transmitida de pessoa a pessoa.

Na moderna economia de mercado, rompeu-se o vínculo entre o produtor e o consumidor, o mercado tornou-se uma entidade abstrata e a comunicação "boca a boca" perdeu sua eficácia. As comunicações de marketing desenvolveram-se justamente com o propósito de manter os vínculos do fabricante com o cliente, atual ou potencial.

O composto promocional é o conjunto dos instrumentos de marketing voltados para informar o cliente atual ou potencial sobre as ofertas da empresa, motivá-lo a considerar essas ofertas como alternativas de compra e persuadi-lo a adquirir os produtos ou serviços da empresa como melhor alternativa para a realização de seus desejos ou o atendimento de suas necessidades.

Promoção é a parte da comunicação que se compõe das mensagens destinadas a estimular as pessoas a tomar consciência dos vários produtos e serviços da empresa, interessando-se por eles e comprando-os.

Existem algumas possibilidades para realizar o trabalho da promoção, são eles: propaganda venda pessoal, promoção de vendas, merchandising e relações públicas.

MÍDIA

Segundo Daniel Okrent, editor de novas mídias da Time Inc. (apud Veronezzi, 2002), "os meios de comunicação não existem para contar às pessoas o que elas querem saber, mas para falarem aquilo que elas não sabem que desejam saber." Para escolher o melhor meio de comunicação, é importante ter em mente que cada um tem uma audiência própria e serve para uma finalidade específica de mídia. A internet vem crescendo rapidamente como meio de 
comunicação, mas sua participação no mercado publicitário ainda é tímida e até mesmo o formato mais eficaz de uso dessa mídia ainda não está definido.

Algumas das formas de propaganda na internet são:

a) Página Web - é o espaço da empresa na internet, constituído através do seu domínio. Pode vender o produto através da internet ou apenas divulgar informações sobre a empresa.

b) E-mail-marketing - é a utilização do e-mail como ferramenta de marketing direto. São mensagens de divulgação da empresa e de seu produto ou serviço enviadas ao consumidor através da autorização prévia do mesmo.

c) Banner publicitário - é algo parecido com um "outdoor" na internet, uma propaganda da empresa num site (preferencialmente de grande tráfego de usuários) que, ao ser clicado, direciona o usuário à página do anunciante.

d) Janela pop-up - consiste numa janela extra que abre no navegador ao visitar uma página web, contendo a informação de anunciante e um link que direciona para a página do mesmo. Hoje em dia, muitos navegadores bloqueiam esse tipo de propaganda, conhecida como "anúncio de interrupção".

e) Pesquisa de opinião pública - é uma enquete desenvolvida e inserida sempre na página principal do site desejado, seja ele de abrangência nacional, regional ou local. A configuração da enquete possibilita um maior controle da mesma (inclusive não permitindo que seja computado mais de um voto por usuário), acompanhamento diário dos resultados e indicação da enquete para amigos.

f) Mecanismos de busca - consiste no aprimoramento do site para que o mesmo tenha uma boa colocação nos sites de busca, como o Google.com. 0 ideal é que o link para o seu site esteja entre os primeiros resultados quando o usuário digita o nome do seu produto num site de busca.

g) Newsletter - diferente do e-mail marketing, o newsletter consiste num boletim digital com diagramação estilo jornal e com periodicidade diária, semanal, quinzenal ou mensal que são enviadas via e-mail. Também conhecido como MEPPS - Mensagem Eletrônica de Publicidade de Produtos e Serviços - é largamente utilizado na divulgação de notícias, suporte técnico, produtos e serviços. 0 envio de newsletter através de email está de acordo com as normas internacionais de marketing por email e anti-spam, e deverá conter opção de remoção do email do usuário que não mais deseje recebê-lo.

Veronezzi (2002) afirma que talvez a internet não seja um novo meio de comunicação, e sim a convergência de todos os meios, já que basta acessá-la para lermos jornais e revistas, ouvirmos rádio, assistirmos TV e filmes. Por outro lado, contrapõe o autor, a internet pode ser considerada algo totalmente novo por possuir algumas características não encontradas nos outros meios, como instantaneidade, megacapacidade de armazenagem, facilidade na busca de informações e direcionamento individual.

Sobre a propaganda na internet, Vaz (2008) afirma o seguinte:

Na internet, a propaganda dá lugar à publicidade, o marketing de interrupção dá lugar ao marketing de relacionamento e de permissão, a forma dá lugar ao conteúdo, a via de mão única dá lugar ao diálogo e à participação, o corporativo ao flexível e orgânico, a 'campanha', à idéia, o marketing de massa ao 
relacionamento com o indivíduo, os segredos da instituição, à transparência absoluta e a empresa cede lugar ao consumidor.

$\mathrm{Na}$ internet, a possibilidade de personalizar o marketing, e consequentemente, de atingir o consumidor, atual ou potencial, é muito maior. Segundo Bishop (2000), a promoção por meio da Internet é mais racional do que emocional, implicando num processo de persuasão e não apenas de informação, que pode variar, evidentemente, conforme o tipo de produto ou serviço.

Ainda segundo o autor, as ações promocionais na internet têm os seguintes objetivos: fornecer informações para consumidores e outros interessados, aumentar a procura, diferenciar um produto ou serviço, incrementar o valor de um produto ou serviço e estabilizar as vendas.

Para Limeira (2002) com a utilização do ferramental Internet, o composto promocional é afetado diretamente no âmbito do marketing direto. A Internet representa um canal adicional para obtenção de informações de produtos e serviços pelos consumidores, mas também para a elaboração de programas de relacionamentos e estratégias de marketing. Com a utilização da Internet, as vendas pessoais passam a ser efetuadas por meio de links interativos entre a empresa e o comprador, e se este assim o desejar, sem a intervenção de um vendedor.

\section{YOUTUBE}

Fundado em fevereiro de 2005, o YouTube é o líder no setor de vídeos online e o principal destino dos internautas para assistir e compartilhar vídeos originais com todo o mundo pela web. O YouTube possibilita que os usuários enviem e compartilhem clipes de vídeo com facilidade no site www.YouTube.com e em toda a internet por meio de sites da web, dispositivos móveis, blogs e e-mails. 0 YouTube rapidamente se tornou o principal destino de entretenimento em vídeo na internet.

Qualquer pessoa pode assistir a um vídeo no YouTube. Elas podem ver relatos de eventos atuais em primeira mão, localizar vídeos sobre seus passatempos prediletos e assuntos de interesse, e até descobrir algumas pérolas. Cada vez mais pessoas estão capturando momentos especiais em vídeo e o YouTube está cuidando de transformá-las nos criadores da televisão do futuro.

Estes são alguns dos recursos do site:

- A incorporação de vídeos, que permite a inserção de um vídeo do YouTube em contas do MySpace, blogs ou outros sites em que qualquer pessoa pode assisti-lo.

- Vídeos públicos ou privados: o usuário é quem escolhe se deseja enviar e divulgar os vídeos publicamente ou compartilhá-los apenas com os amigos e familiares.

- As inscrições permitem que os usuários fiquem a par dos novos vídeos dos seus usuários favoritos.

- Captura rápida: usuários providos de uma webcam e do software Flash podem gravar respostas em vídeo ou vídeos comuns diretamente no site, em vez de gravá-los previamente para enviar para o YouTube.

- TestTube: trata-se de um espaço do site em que os engenheiros e desenvolvedores do YouTube realizam testes alfa para novos recursos em desenvolvimento. O YouTube também 
incentiva a participação dos usuários no processo de desenvolvimento e na avaliação desses recursos.

Usuários registrados podem enviar e compartilhar vídeos, salvar favoritos, criar listas de reprodução e fazer comentários sobre os vídeos. O YouTube está construindo uma comunidade altamente motivada para assistir e compartilhar vídeos. O serviço do YouTube é gratuito e será patrocinado por publicidade.

O interesse no site continua a crescer numa taxa impressionante. Enquanto eles estão mais focados em fornecer à comunidade os recursos que ela pede e oferecer aos usuários a melhor experiência possível do que em calcular números, o You Tube continua sendo líder no segmento de vídeo on-line.

A faixa etária da base de usuários do You Tube é de 18 a 55 anos, abrangendo todas as regiões geográficas. Com uma base tão grande e diversificada, o YouTube oferece algo para todos.

\section{O CASO NO HOTEL SUL AMERICA}

Localizado em São Lourenço, tradicional Estância Hidromineral do Sul de Minas, o Hotel Sul América oferece uma enorme infra-estrutura de lazer e entretenimento.

São Lourenço é a mais jovem estância de Minas Gerais e a mais completa em infra-estrutura, alegre e encantadora, de solo abençoado por suas águas, destaca-se em qualidade de vida. A cidade oferece diversas alternativas de lazer: o Parque das Águas - com sua vegetação nativa, fontes de águas minerais, bosques, duchas e a energia do ar das montanhas. Lugar ideal para o descanso do corpo e da mente; A Fundação Cima's - onde vida saudável e arte se encontram; o Memorial Tancredo Neves - o mais alto monumento da cidade; a Eubiose - que se dedica ao estudo de todas as religiões; o Trem das Águas - um nostálgico percurso numa Maria Fumaça do século XIX, além do teleférico e dos passeios de charrete ou a cavalo por antigas fazendas.

Aliada a qualidade dos serviços, toda estrutura vem sendo modernizada no sentido de oferecer aos seus visitantes conforto e entretenimento. Possui piscinas naturais e térmicas, com avançado sistema hidráulico que gera movimento às águas, forma um belíssimo conjunto de duchas, chafarizes e quedas, garantindo momentos de repouso e descontração. A programação do Hotel inclui festas, por vezes típicas ou temáticas, que já se tornaram prestigiadas com a apresentação de bandas musicais e sempre registrada pou um hospede satisfeito que acaba por publicar o vídeo no youtube.

\section{O HOTEL SUL AMÉRICA E O YOU TUBE}

Ao se digitar Hotel Sul América na barra de pesquisas do Youtube o resultado pode parecer um tanto desanimador. Apenas quatro vídeos com pouco mais de 2200 exibições, tal qual o exemplo a seguir: 




Fonte: www.youtube.com

A cidade de São Lourenço sempre foi conhecida como um centro de lazer para pessoas maduras, que se interessam em desfrutar da tranquilidade local e se recompor espiritualmente nas aguas do parque, entretando, o vídeo mais assistido(1877 exibições) refere-se a um passeio de jovens e adolescentes que aconteceu em2007.

Em seguida destacavam-se dois comentários de jovens que não participaram da viagem. 0 primeiro ressaltava que aquele era o "MELHOOR HOOTEEL *-----*" e que o autor da frase frequentava desde pequeno. 0 segundo dizendo que curtiu muito e queria saber onde ficava $o$ hotel.

Pesquisando a estatística do vídeo, percebemos que por 23 vezes ele foi assistido de dentro dos computadores do Hotel Sul América, o que caracteriza duas situações: hospedes conferindo a viagem de outros ou membros do hotel investigando o site.

Muitos vídeos relacionados faziam referencia a cidade de São Lourenço o que é bastante interessante para o turismo local.

O segundo vídeo mais acessado (160 exibições) foi postado por um casal que passou a lua de mel no hotel, trata-se de uma cena da nova piscina que foi construída no terraço do hotel. Avaliando o perfil do usuário que postou o vídeo identificamos apenas 3 vídeos, todos relacionados ao casamento, e esse foi o mais assistido (curiosidade: os noivos não aparecem, somente o hotel). 
Os outros dois vídeos, cada qual com cerca de 200 exibições dizem respeito a uma brincadeira entra adolescentes na sala de internet e um show de uma das bandas que tocam nas festas promovidas. Também achamos um outro vídeo sobreo hotel quando digitamos "hotel sulamérica" (tudo junto). Trata-se de uma família vendo televisão em uma das suítes.

O que é interessante de se destacar é que muitas das atrações do hotel são apresentadas através desse marketing viral ou seja, aquele produzido pelos consumidores e que se distribui através das rede pessoais. Podemos totalizar assim cerca de 2500 exibições de vídeos relacionados ao Hotel Sul América todos desenvolvidos por consumidores que manifestaram sua satisfação em relação ao que vivenciaram.

Em seguida, foi elaborado um questionário para estudar o caso do Hotel Sul América. Na primeira pergunta, questionava a idade média dos frequentadores do hotel. Eles informaram ter claramente perfil dos clientes: público prioritariamente jovem durante o período de férias e mais adulto na inter-temporada .

A segunda pergunta indagava o Hotel sobre a utilização da internet como forma de propaganda. Eles responderam que confiam muito no site do hotel na internet e que consideram esse espaço o grande veículo de propaganda do hotel.

Mas em relação a outros sites, como o Youtube e Orkut, eles alegam não ter um trabalho específico pois não se trata de canal oficial do hotel.

Quando informamos que o vídeo mais acessado tinha quase 2000 exibições e era um vídeo muito positivo a respeito do hotel, a reação foi de surpresa (pois eles já haviam alegado não pesquisar informações sobre o hotel nesses sites) e admiração pois trata-se de um número expressivo. Na opinião deles esse fato está mais relacionado com o Orkut, pois os jovens o utilizam muito e o site permite link direto com o Youtube. Quando um hospede fica muito satisfeito com hotel e mostra o vídeo para seus amigos e colegas de trabalho e o youtube é um excelente espaço para isso.

A terceira pergunta questionava o hotel sobre o fato de algum hóspede já ter mencionado ter visto algum vídeo presente no Youtube de hóspedes que passaram férias ou algum feriado e gostaram do local e assim começado o interesse em conhecer o local. A pessoa que respondeu pelo hotel respondeu que não, porém, com cerca de 2500 exibições, achamos difícil não haver nenhum comentário, pelo menos entre os próprios hospedes. Eles parecem acreditar que o Youtube possa ser um meio de comunicação, mas entendem que as pessoas ainda podem não perceberam credibilidade a vídeos não oficiais.

A quarta e última pergunta questionava-os sobre a existência de um vídeoinstitucional e se existia o interesse por parte deles de divulgar este vídeo no YouTube. A resposta do Hotel é que existe sim um vídeo institucional e que eles faz em um trabalho específico com grupos de viagens e corporativo de empresas. Não acham muito interessante disponibilizá-lo no Youtube normalmente recorrendo a questão da credibilidade.

\section{CONCLUSÃo}

Segundo pesquisa da Midia-Screen, realizada no inicio deste ano, com quinhentas pessoas que assistiram vídeos na Internet nos últimos trinta dias, mais de $60 \%$ dos usuários do YouTube têm entre 15 e 34 anos, público jovem que é o mesmo público que costuma frequentar o Hotel.

No início da pesquisa, o Hotel não possuia vídeos institucionais no YouTube. Somente vídeos 
de pessoas que se hospedaram, filmaram sua temporada no Hotel e compartilharam o vídeo no site. Porém, acreditamos que a entrevista possa ter despertado o interesse do pessoal no site. Até porque só encontramos referências positivas em relação do hotel e também porque outros hotéis da região já estão usando essa forma de atuação.

Por existir há pouco tempo, o YouTube ainda não é muito explorado para propaganda - os vídeos postados no site, na sua maioria, são vídeos caseiros, clipes de música, fotos e etc. Os motivos para a não utilização do site como ferramenta de promoção podem ser: a falta de conhecimento ou a falta de crença de que o site pode ser uma forma simples e rápida de chegar ao público-alvo. Sugerimos, a guiza de recomendação final, que outros estudos possam ser realizados a fim de avaliar porque algumas empresas ainda não confiam no site.

De modo geral percebemos que este cenário está mudando. Pequenas e médias empresas estão começando a demonstrar interesse em utilizá-lo como meio de promover-se, através da inserção de vídeos institucionais, promocionais e divulgação de campanhas. O Hotel Sul América demonstrou, a partir deste trabalho, interesse em entender um pouco mais o YouTube como forma de divulgação inevitável nos dias atuais. Sem dúvida as pessoas vão postar cada vez mais vídeos falando sobre a experiência que viveram com os produtos e serviços. Dessa forma as empresas podem ter um feedback dos clientes, inclusive porque eles podem incluir comentários e avaliações dos vídeos, podendo inclusive, ajudar na melhoria do serviço prestado. Sugere-se, por fim, para os próximos trabalhos que sejam avaliados outros hotéis da região, como forma de medir a competitividade local. Além disso, podem ser exploradas as outras ferramentas como o Orkut e o Twitter.

\section{REFERÊNCIAS BIBLIOGRÁFICAS}

COBRA, Marcos. Marketing Básico. São Paulo: Atlas, 1997.

KELLER, Kevin Lane \& KOTLER, Philip. Administração de Marketing. São Paulo: Pearson Education do Brasil, 2005.

KOTLER, Philip. Marketing de A a Z: 80 conceitos que todo profissional precisa saber. Rio de Janeiro: Campus, 2003.

Las Casas, Alexandre. Marketing: Conceitos, exercícios, casos. São Paulo: Atlas, 2005.

Rocha, Ângela da; Claristensen, Carl. Marketing: Teoria e Prática no Brasil. São Paulo: Atlas, 1999.

Schewe, Charles e Smith, Reuben. Marketing: Conceitos, casos e Aplicações. São Paulo: Makron Books, 1982.

VERGARA, S. C. Projetos e Relatórios de Pesquisa em Administração. São Paulo: Atlas, 2001.

http://www.almanaquedacomunicacao.com.br/artigos/575.html Acessado em 08/11/2008 às $14: 30 \mathrm{~h}$

http://br.youtube.com/t/about Acessado em 04/10/2008 às 10:00hs

http://www.fatea.br/janus/pdfs/artigo07.pdf Acessado em 08/11/2008 às 15:00hs

http://www.infoescola.com/comunicacao/midia Acessado em 08/11/2008 às 16:00hs 